\title{
IMPLICATIONS, LARGE AND SMALL, FROM CHEMICAL EDUCATION RESEARCH FOR THE TEACHING OF CHEMISTRY ${ }^{\#}$
}

Peter J. Fensham

Faculty of Education, Monash University, Clayton, Vic., Australia 3168

Recebido em 01/10/01

\begin{abstract}
Research studies in chemical education pose a communication problem for chemists. Unlike the findings from other specializations in chemistry the findings in chemical education tend to be reported in education journals that are not readily accessible to most chemists or chemistry teachers. This lecture is an attempt to remedy this gap in communication.

Research studies fall into three broad categories.

(i) issues related to the content of chemistry itself, that is, What content to teach? And What meaning of each topic is to be conveyed?

(ii) issues related to how chemical content is taught, such as, the role of lectures, practical work, particular pedagogies, etc. and (iii) issues related to its learning, that is, learning of concepts, conceptual change, motivation, etc.

Findings in each of these categories of research over the last twenty years have drawn attention to opportunities for improving the quality of chemical education in each of the levels of formal education where chemistry is taught.

Sometimes the research findings seem small since they, in fact, merely diagnose the actual problem in teaching and learning. At other times, the research findings are large because they provide a solution to these problems. What remains to be done is to disseminate the findings so that appropriate teaching occurs more widely, with its consequent gains in the quality of learning. Research findings, of these small and large types will be used to illustrate the potential of research to make the practice of chemical education more effective.
\end{abstract}

\section{INTRODUCTION}

Research in chemical education is still rather a young field. It emerged from the very energetic activity in the 1960s and 1970s in a number of countries to create new curricula for school chemistry after a long period of stagnation. There was virtually no substantive research in chemistry teaching and learning on which these new curricula could draw. They thus drew largely on the enthusiastic ideas of the project teams and on more general ideas from psychological studies in instruction and learning.

The initial research studies were directed at assessing the influence of the new curricula and their supporting materials. In general the findings were very sobering. The high hopes of what a set of new curriculum ideas and materials might do for school science were rarely borne out in the practice of ongoing school systems. Teachers found it hard to teach in the ways the curriculum designers intended. Students still found chemistry hard to learn. Examinations were not adapted to reinforce the new objectives. Even among the more successful instances, students achieving well in the examinations were often found to have only shallow and algorithmic understanding of the chemical concepts that were now central features of the intended learning.

Three major reasons have been identified for these disappointing findings. Firstly, too much of the resources of the projects went into producing the set of new materials, and far too little into preparing and equipping teachers for these new ideas.

e-mail: peter.fensham@education.monash.edu.au

\# Conferência apresentada na $24^{a}$ Reunião Anual da SBQ, Poços de Caldas, 28 a 31 de maio de 2001
Secondly, the social context of schooling when these projects were launched had changed by the time their ideas and materials were ready to be put into practice. In the early 1960s in most countries chemistry in school was only studied by an elite group of students in the upper secondary school. Already by the 1970s, this elitist nature of upper secondary school was beginning to change, and chemistry needed to attract and make sense to a wider and more diverse crosssection of students. In the 1980s, the demography of secondary school science changed again as more female students and other, hitherto under-represented social groups, began to seek full secondary education. In this period in several countries new subjects appeared in the school curriculum, and some of these like Computer Studies, began to compete vigorously with chemistry for the students' interests.

Finally, the teaching and learning of a subject like chemistry turns out to be more complex than the enthusiasms of the 1960s had imagined. Chemical education needed a more substantial research base of its own, on which to base innovations and the preparation of its teachers at each of its levels in the education system.

\section{Problems of teaching and learning chemistry}

There are two distinct stages in the solution of problems. The first stage is concerned with diagnosing what is wrong in a more precise form. This identification may seem only a small step to solving the problem, but it is quite essential. The second stage involves the moves towards a solution. Initially these often lead to a solution in rather specific instances of the problem, and this solution needs then to be extended more generally, and disseminated to teachers. Nevertheless, these first solutions are a large achievement holding the promise of more general solving.

If the problem is how to improve the quality of chemistry teaching and learning, research in chemical education has, I believe, achieved some notable successes in relation to both these stages of the problem 
solving. In this paper I want to consider a number of problem areas for the teaching and learning of chemistry and, for each one, to share with you how research has contributed to both the small and large stages of their resolution.

\section{SMALL IMPLICATIONS: DIAGNOSES OF PROBLEMS}

Among the studies that have been diagnostic in character are:
(a) students' alternative conceptions
(b) students' spatial recognition and visualisation
(c) problem solving in chemistry
(d) modes of instruction and sequence of instruction and
(e) chemistry as problematic knowledge.

\section{(a) Studies of students' alternative conceptions}

The 1980s saw a quite remarkable shift in the focus and the methodology of research in science education. The quasi-experimental studies of various instructional modes with quantitatively measured dependent and independent variables, gave way to interview studies with individual students about specific science phenomena. These yielded qualitative data that could be analysed in ways that contributed to understanding the conceptual development of students. By the end of the decade, several thousand of these studies had been reported with a surprising level of commonality in the findings.

Students do not come to the study of the sciences with blank minds. They have prior ideas or conceptions about a number of the scientific phenomena and the concepts of introductory chemistry in particular. Many of these ideas are held very firmly despite being different from, or alternative to, the current chemical understandings as presented in textbooks and by their teachers.

\section{Particulate nature of matter and changes of state}

The particulate nature of matter has been the most studied chemical topic. Stavy ${ }^{1}$ in Israel reported on students' understanding of gases and on gaseous changes of state, a topic explored earlier by Osborne and Cosgrove ${ }^{2}$ in New Zealand and more recently by Renström, Andersson and Marton ${ }^{3}$ in Sweden. Wherever these studies are conducted, very similar alternative conceptions are found to be commonly held, even among the "successful" students.

For example, students will glibly describe air as consisting of small moving particles called molecules, but when asked, "What is between the particles?", they will say "Air."

Again, the bubbles observed when water is boiled are seen as 'air', 'heat', 'hydrogen and oxygen' and 'steam'. The percentage prevalence of these views at age 12 was $30,30,24$ and 16 respectively. By age 17, after considerable chemistry teaching, they were 25,3 , 36 and 36, indicating more recognition of the bubbles as substance, but still great confusion over what the substance is.

\section{Chemical change}

Andersson ${ }^{4}$ used several obvious reactions, including the burning of iron wool on a balance pan, to explore the ideas adolescents in Sweden had about chemical change. These ideas could be classified into five alternative conceptions, only one of which (for about 20\%) is consistent with the sense in which 'chemical change' is now used in chemistry. Hesse and Anderson ${ }^{5}$ in the USA, using a similar methodology found much the same range of ideas but, in addition, described in more depth the failure of many of the students to comprehend that matter is conserved in chemical change, as well as in physical changes.

\section{(b) Studies of spatial recognition and visualisation}

The chemistry of many substances soon involves three types of spatial ability.

1. Visualisation: The accurate perception of the spatial pattern in 3-dimensional objects from 2-dimensional representations.

2. Orientation: How a representation changes from different perspectives.

3. Operation: The effects of rotation, reflection and inversion on 2-dimensional representations of 3-dimensional objects.

Pribyl and Bodner ${ }^{6}$ tested undergraduate students' spatial abilities and analysed how these related with achievement on organic chemistry tests, that involved mental manipulative skills. The gross correlations were not high, but when more fine-grained categorisation of the mental skills in each item were used, the correlations revealed subtle connections between the students' with different levels of the spatial abilities.

Tuckey and Selvaratnam ${ }^{7}$ studied the difficulties second year undergraduate chemistry students had with the rotations and reflections of 3-dimensional structures in organic and organo-metallic chemistry. They designed tests that were based on items that tested just one of the elementary concepts or skills required in the more traditional questions about these substances. This enabled particular learning difficulties to be pinpointed.

\section{(c) Studies of problem solving}

Problem solving has been a major research field in science education, particular where the procedures involve quantitative calculations. There is an accumulation of experience and research findings that much of the 'successful learning' of these procedures is merely algorithmic in character, and thus breaks down when the problems are posed in unfamiliar ways, or set in novel contexts. In chemistry these findings have been established in relation to quantitative problem solving in stoichiometry, chemical equilibria, and redox. Solving qualitative problems in organic synthesis and spectral recognition have also been studied, and although these are not so susceptible to simple rule learning, they involve other interesting issues.

The commonest way to investigate both types of problem solving is to compare how 'experts' and 'novices' approach a type of problem.

\section{Electrochemical cell and redox problems}

Lee $^{8}$ found that her 'experts' ( senior secondary chemistry teachers), compared with her 'novices' (their students) spent considerably more time identifying exactly what the problem was, selecting the strategy to use in moving to a solution, and checking at each of the steps. She went further than most problem solving studies by observing how these 'experts' taught this type of problem solving. In general, they spent little or no time with their students identifying the problem they were demonstrating. They taught by demonstrating a single strategy, and not by discussing it. Finally, they rarely emphasised checking as part of the process of moving to a final solution.

\section{Identifying unknown compounds from spectra}

Spectral information is a powerful means whereby chemists can identify features of unknown substances. There are, however, inherent difficulties in teaching this use of spectral information. One of my research students was able to study this problem by taking advantage 
of the fact that one of the chemistry professors was engaged at the time in an early attempt to harness the computer in resolving mass spectral data. ${ }^{9}$ She found that "experts" when resolving these spectra reached a point in their analysis when they called on their earlier experiences of solving other spectra to compound identifications. "Last time I saw a spectra like this it was X so I'll try something like that." This strategy was the human equivalent to a computer checking the spectral data of an unknown substance against a large index of such data in its memory bank. Neither of these strategies - the selective memory of experience or the large memory bank - is available to a 'novice'.

The second difficulty lies in the fact that the correspondence in going from the spectral characteristics of the unknown to it, as a known substance, is not a simple one-to-one relationship. In this case it was again interesting to observe that when this use of spectra was being taught in Physical or Organic Chemistry, it was taught by using a known substance to illustrate the principles of the spectral analysis, rather than by using an unknown example. For the case of known substance to spectra, the relationship is a simple one-to-one correspondence.

\section{(d) Studies of modes of instruction/learning}

\section{Lecturing chemistry}

A very common instructional mode for university chemistry is the lecture. Regardless of the size of the class, an instructor delivers a lecture for about one hour making considerable use of the blackboard, or overhead projector, or more recently Power Point generated visuals. There may, or may not, be an occasional pause for questions, but primarily the instruction is one-way transmission with the students left to make notes of what is presented. A number of studies have been made of the learning that occurs in this situation. One study found that the attention of the students tended to wax and wane. That is, it will start low but rise to a high level for 15 or so minutes after which it will decline, with shorter subsequent highs and lows.

Bucat and Williams ${ }^{10}$ found that the students' record of the lecture was almost always restricted to what the lecture presented visually, and little or none of the instructor's additional and explanatory comments were recorded. A few students made an almost complete record of the visual material and the rest had less complete records. They also found that the amount of visual material in an hour could vary by $100 \%$ from instructor to instructor. Other studies have found that undergraduate chemistry students focus their subsequent learning on the record they have of the lectures. The combination of limited records, and their importance as the source for learning, account for the rather shallow learning that is so often found among even the 'successful students'.

\section{Learning in the laboratory}

A number of studies have questioned the efficacy of the learning that results from the many hours students spend in chemical laboratory work - an expensive mode of instruction. In schools it is common for students to work in small groups in the laboratory. Klainin ${ }^{11}$ in Thailand tested a number of classes of students some weeks after they had completed a practical exercise. More than $80 \%$ of the student groups successively repeated the practical exercise. Soon after, she re-tested the students, individually and in isolation. Now only about $20 \%$ were successful. White ${ }^{12}$ has discussed other studies that have reported only minimal conceptual gains by students, who carry out a series of practical exercises that might have been expected to provide images and episodes that would reinforce the theoretical teaching.

Some overall findings about practical work are:

- students engage in with the practical tasks instrumentally by observing and following other students, and

- students use the notes for the practical exercise as a step by step recipe, giving little cognitive attention to the investigation as a whole.

\section{(e) Chemistry as problematic knowledge}

Most of the studies discussed so far have concentrated on the 'education' aspect of chemical education as the source of the breakdown of quality teaching and learning. The final group of studies focus on the 'chemistry' aspect itself. Most of these studies are continental European in origin.

A provocative example of this type of study can be found in a lecture by de $\operatorname{Vos}^{13}$ It was entitled, Is Chemistry a Science? He first charmed his audience of chemists by defining a Science as a field that has clearly defined and unambiguous concepts. He then proceeded to take a number of fundamental concepts in chemistry like a molecule, an atom, and chemical change. For each of the agreed statements of these concepts, he gave examples that showed fuzziness, or a lack of clarity in the statement.

Drawing on his research into the questions beginning students ask, he raised doubt about how well Chemistry's fundamental concepts met the criterion of a Science. He went on to acknowledge that, when chemists know enough chemistry, they find these concepts useful and are not impeded by this fuzziness. In the teaching of Introductory Chemistry, he argued, too often there is insufficient recognition of the learning problems these concepts present to students. He advocates an initial approach through the experience of interesting reactions, rather than through the more common one via atoms and molecules.

\section{Sequence of instruction: Teaching and learning topics in isolation}

One good measure of the depth of learning, or level of understanding, is the number of connections or linkages a learner can make for any given topic. Related to this is the learner's ability to transfer learning in a given context to other different but related contexts.

A powerful tool to measure a student's ability to make these linkages is the concept map. It has been used in many research studies of the depth or quality of learning.

Studies of how chemistry is taught in both universities and schools have revealed a surprising disjunction within and between topics. Well established sciences like physics and chemistry are usually thought to be quite sequential in development, with considerable building on concepts to develop more complex ones and the knowledge as a whole. Studies of how students see one topic relating to an earlier or subsequent one reveal that they lack the connectedness that might have been assumed. Textbooks also reveal some surprising disjunctions. They are set out in a very linear fashion with relatively little cross-referencing back and forth. One common example is the introduction of oxidation and reduction in inorganic and redox reactions in terms of the transfer of electrons in inorganic chemistry. A few chapters later oxidation and reduction in organic chemistry is portrayed with a square bracketed symbol over the arrow in the reaction statement, with no indication at all about the transfer of electrons

\section{Levels of representation}

One of the very common features of chemistry as a science is the repeated movement that occurs from the macroscopic level of 
substances to the sub-microscopic level of atoms and molecules and the symbolic ways in which these levels are represented in chemistry.

Consider the reaction equations for the solution of silver nitrate in water, and for the displacement of copper in solution by zinc.

$$
\begin{aligned}
& \mathrm{AgNO}_{3}(\mathrm{~s}) \rightarrow \mathrm{Ag}^{+}(\mathrm{aq})+\mathrm{NO}_{3}^{-}(\mathrm{aq}) \\
& \mathrm{Zn}(\mathrm{s})+\mathrm{Cu}^{2+}(\mathrm{aq}) \rightarrow \mathrm{Zn}^{2+}(\mathrm{aq})+\mathrm{Cu}(\mathrm{s})
\end{aligned}
$$

Do the symbols in these chemical statements refer to the macroscopic level or the atomic/molecular level or to both?

Johnstone ${ }^{14}$ was able to associate many of the learning difficulties he had found with the tendency among chemistry teachers to switch between these levels without explanation, even when the switch is not necessary.

\section{Representation of organic substances}

Kellett ${ }^{15}$ followed up a research finding, that esterification was a topic students in Scotland found difficult, with an elegant study of how beginning students in organic chemistry read organic formula, and how they coped with the many level and symbolic changes that occurred in these early lessons. Johnstone and Kellett ${ }^{16}$ reported that many of them tried to read these formulae from left to right as they would read other messages in English. The symbolic conventions in organic chemistry usually present the functional group, the most significant part of the formula, at the right hand end of the formula. Some of these students have not got that far in their reading before the discourse of the lesson moves on to present other substances, often only by fragmented forms of their symbolic or molecular formula. These authors found that the students' recognition of these formulae followed well-known principles of information reception theory. Accordingly, these early lessons in organic chemistry very often produced information overload. They recommended that teachers should maintain, during these early lessons, a consistency of substance representation, and that the use of other symbolic means of highlighting the key information could provide a more solid foundation for learning later complexities in this very symbolic area of chemistry.

The third example of problematic chemistry is probably the most studied topic in chemical education. Researchers in countries that fall in the Anglo-American orbit of influence often refer to their study as being of 'the problem of the mole concept'. However, one does not find among these researchers parallel studies of the 'problem of the second concept' or 'the problem of the metre concept'.

The mole is officially merely the SI unit for the quantity concept, amount of substance. Chemists argued strongly for the SI System to include amount of substance as a fundamental quantity with the mole as its unit. The reference to 'the problem of the mole concept' by so many teachers and researchers in chemical education and their reference to the mole as a number indicates a real confusion in the field. European researchers like Dierks ${ }^{17}$ and Strömdahl, Tullberg and Lybeck ${ }^{18}$ have found this confusion extends to textbooks and even among university professors of chemistry. They tend to suggest that Chemistry's official position about what is the concept and how is its quantity measured should be rethought, since it is so confusing to teach and learn.

\section{LARGE IMPLICATIONS: SOLUTIONS TO PROBLEMS}

\section{Students' alternative conceptions}

Fortunately, a number of researchers have not been content to simply go on presenting the amazing range of ideas students have about chemical phenomena, although a great deal of this has been done for masters and doctoral degrees. The discovery of alternative conceptions and their persistence in the face of teaching has challenged researchers to find ways of changing these conceptions towards the current scientific ones. Mitchell and Gunstone ${ }^{19}$ reported the presence of five common alternative conceptions among the students in a class studying stoichiometry. For the next year of teaching Mitchell ${ }^{20}$ devised a very different teaching approach in which he specifically addressed these alternative ideas with the students. The worth of this extended attempt to change these ideas was rewarded by the fact that now two thirds of the class now achieved in tests at the levels previously only reached by one third. Mitchell ascribes the continued failure of the bottom third of the students to the constraint of maintaining the same total teaching time in each year. More time was needed, he suggests, if the deep-seated ideas of these students were to be changed.

\section{Research into Practice}

An opportunity arose about a decade ago to test whether what we knew, from the studies of the problems in lecturing, practical work and patterns of teaching, could be remedied to improve the quality of both teaching and learning. The Engineering Faculty of my university had hitherto required its entering students to have successfully studied chemistry, physics and mathematics in the final two years of senior secondary school. As the diversity of subjects in these years increased throughout the 1980s, it became clear to the newly appointed Dean of Engineering that this requirement was excluding some very able students, who had studied two of these subjects at school, but not the third. He offered the science educators in the Faculty of Education a contract to teach such students a onesemester course of Chemistry that would enable them to enter Engineering Chemistry in the second semester of their first year of the Engineering program as a whole.

After a careful study of the implicit language and prior knowledge of chemistry that the lecturers in Engineering Chemistry assumed, a course for this Bridging Chemistry was designed, consisting of thirteen weeks with four lecture classes per week and two hours of laboratory practical work. The central tenet was that the students should be actively, minds-on learning during each of these six hours ${ }^{21}$. To enhance this level of attention during the class sessions, lecture notes were issued but on each page there were a number of critical gaps of words, data or a diagram. Students were thus able to attend to the teacher's words and explanations, and to write only minimally, but very importantly, to fill these gaps. They were also taught to ask questions, and there were regular pauses for this to occur. Students were given credit for what they learnt were higher level questions. The printed notes also included questions and small tasks for which time was again allowed, ensuring the students were following the development of the topics. Sharing their responses provided immediate feedback to the lecturer about the students' prior conceptions and comprehension.

In the four hours of class teaching a wide range of teaching strategies was used. Interestingly, many of these, like concept mapping and Venn diagrams, had initially been tools that researchers developed for probing and measuring the strengths and weaknesses in student learning. In the process of using these with individual students, it was not uncommon for researchers to observe an " $A h H a$ " response, as the student for the first time realised that this piece of his/her knowledge could be related to another piece. Accordingly, it was natural to start using these research tools as teaching strategies. Others of these strategies were Predict-Observe-Explain demonstrations, Create sub-headings in notes, Compare sets of data, Translate words into graphs, Change representation level, etc.. 
The two-hour practical session each week consisted of practical investigations that involved the theoretical content of the previous four hours of teaching. Before the students could begin the practical work, they were required to answer three short, but penetrating Thinking Tasks about it, to minimise the mindless recipe following. At the end of the practical exercise, there were also some Follow-Up Questions to answer to give point to the results of the practical work, but also to extend and relate their findings to the theoretical ideas in the course.

Some of the Thinking Tasks were:

- Design your own method,

- Unscramble the random set of steps for the investigation,

- Prepare a flow chart of the steps and the calculations that are involved,

- Decide which quantities need accurate measures,

- Link the practical instructions to theory, etc..

Evaluations of this teaching approach over almost ten years has shown high levels of mastery by the students and, more significantly for the Engineering Faculty, the students performed as well or better in Engineering Chemistry, than the traditional entry students who had had chemistry at school. One other plus for these bridging courses and their methods of teaching was the fact that they more than doubled the number of female student in Engineering.

\section{Teaching bonding and structure in organic chemistry}

An interesting example of teaching directed at one of the problems in chemistry content is the study by van Hoeve-Brouwer ${ }^{22}$ in The Netherlands. He discusses what he calls the "gap" or major inconsistency in text-book presentations of the conceptual approach to teaching bonding from the properties of the free atom (based on energy levels and energy of ionisation) and those of the bonded atom. This essentially physics approach to a central feature of chemistry is underpinned by the reductionist sense that physics is the fundamental science and the assertion that chemical structures can be derived from first principles. Van Hoeve-Brouwer argues that even were this to be true in principle, it cannot be demonstrated to chemistry students when they study this topic in chemistry. He then, in a very elegant fashion, develops with teachers and students a chemical approach, which involves the reaction properties of a particular substance for discerning its molecular structure. The substance he chooses to illustrate this chemical approach is butendioic acid, with its isomeric forms - maleic acid and fumaric acid. The substance has a long history in chemistry and the teachers and the students become involved in this history by repeating some of it, including Pelouze's experiment of 1834 to determine the empirical formula. The Structure-Properties approach involves observing properties, representing them in formulae, and using these formulae to describe, explain and predict other properties. The approach can be followed by students at each step, and in addition, they gain a rich understanding of the nature of chemical inquiry itself.

\section{Visualisation}

My final example of a solution or large implication exemplifies the potential there now is to draw on the research base, in combination with imaginative use of computers, to achieve learning aids that were impossible earlier. One example of these new teaching tools is VisChem, available in video or CD form, for assisting students to visualise structures and reaction processes in chemistry. ${ }^{23}$ VisChem was developed from a research base that included alternative conceptions, levels of representation, the need for dynamic models, and for concentrations to be as authentic as possible.

The topics for which VisChem materials are now available are The Molecular World of Water, Solids Liquids, Gases. and Reactions in Water : Dissolving, Precipitation, and Complexation.

\section{REFERENCES}

1. Stavy, R.; Int. J. Sci. Educ. 1988, 10, 553.

2. Osborne, R.J.; Cosgrove, M.M.; J. Res. Sci. Teaching 1983, 20, 825.

3. Renström, L.; Andersson, B.; Marton, F.; Journal of Educational Psychology 1990, 82, 555.

4. Andersson, B.; Sci. Educ. 1986, 70, 549.

5. Hesse, J. J.; Anderson, C.W.; J. Res. Sci. Teaching 1992, 29, 277.

6. Pribyl, J.R.; Bodner, G.M.; J. Res. Sci. Teaching 1987, 24, 229.

7. Tuckey, H.;Selvaratnam, M.; Studies in Science Education 1993, 21, 99.

8. Lee, K.W.; Research in Science Education 1985, 15, 43.

9. Fensham, P.J.; Nickless, K.; Research in Science Teaching 1975, 5, 43.

10. Bucat, R.; Williams, R.; Research in Science Education 1989, 19, 37.

11. Klainin, S.; Fensham, P.J.; West, L.H.T.; Int. J. Sci. Educ. 1989, 11, 101.

12. White, R.T. In Learning Science 1988, p. 186.

13. de Vos, W. In Unpublished lecture to Monash Univ. Chemical Society, July 1997.

14. Johnstone, A.H.; Journal of Computer Assisted Learning 1991, 7, 701.

15. Kellett, N. C.; Johnstone, A.H.; Educ. Chem. 1974, 11, 111.

16. Johnstone, A.H.; Kellett, N.C.; Eur. J. Sci. Educ. 1980, 2, 175.

17. Dierks, W.; Studies in Science Education 1981, 8, 93.

18. Strömdahl, H.; Tullberg, A.; Lybeck, L.; Int. J. Sci. Educ.1994, 16, 17.

19. Mitchell, I.F.; Gunstone, R.F.; Research in Science Education 1984, 14, 78.

20. Mitchell, I.F.; MEd Thesis, Monash University, 1984.

21. Mitchell, I.F.;de Jong, E.J.; Higher Education Research and Development 1994, 13,1.

22. van Hoeve-Brouwer, G.M. In Teaching Structures in Chemistry: An educational structure for teaching chemical bonding,. University of Utrecht, 1996.

23. Tasker, R.F. In Chemistry: Expanding the Boundaries, $14^{\text {th }}$ ICCE Conference, Chemistry Department University of Queensland, p. 225. 